\title{
A New Technique of Mitral Valve Replacement With a Homologous Aortic Valve
}

\author{
Akio Suzuki M.D. and Earl B. Kay M.D. \\ The Department of Thoracic and Cardiovascular Surgery, \\ St. Vincent Charity Hospital, Cleveland, Ohio U.S.A.
}

\begin{abstract}
This is a preliminary report of a new technique of mitral valve replacement with a homologous aortic valve. Our experimental studies showed low operative mortality and excellent hemodynamic results up to date. No thromboembolic complication has been observed. The fate of homologous cardiac valve is discussed. One successful human mitral valve replacement with up-side down homologous aortic valve is reported.
\end{abstract}

$\mathrm{M}^{\mathrm{n}}$ ITRAL prosthesis with the KAY-SUzUKI discoid valve has shown superior hemodynamics and less thromboembolism compared with ball valve prostheses, as reported elsewhere ${ }^{1)}$. However, prosthetic mitral valves, regardless of their type, present a few problems, such as 1) limited space for prosthetic valve insertion in cases with extremely small ventricular cavity, and 2) necessity of permanent anticoagulant therapy. It is generally agreed that homotransplanted cardiac valves have functioned satisfactorily for years with no evidence of rejection phenomena by the recipient, and that thrombus formation is unusual on homografted cardiac valves.

In spite of a large number of successful aortic valve homotransplantations reported by $\operatorname{Ross}^{2) 3)}$ and BARret-BOYEs ${ }^{4)}$, the only successful mitral valve homotransplantation has been reported by HeIMBECKer and his associates $^{6)}$, whose patient died one month later because of infection and electrolyte disturbance. The largest problem of mitral homotransplantation seems to be its anatomical complexity and the technique of obtaining a perfect fixation with competency of the valve. This demands highly developed and skillful surgical technique.

Since 1962, considerable studies have been performed on the problem of homotransplantation of mitral valve in our laboratory. The technique described in this paper has shown the most gratifying results.

\section{Methods}

\section{Preparation of Donor Valve}

With sterile technique, an aortic valve was excised from a mongrel donor dog weighing $18-30 \mathrm{~kg}$ more than the recipient. It was fashioned 1 to 2 $\mathrm{mm}$ distal from the commissure level of the aortic valve and proximally 2 to $3 \mathrm{~mm}$ from the bottom of the cusps, detaching ventricular muscle as much as possible, (Fig. 1). The coronary artery orifices were closed with 5-0 atraumatic silk suture. The donor valve was then placed in $50 \mathrm{cc}$ normal saline, containing 1 million units of penicillin, $1 \mathrm{gm}$ of streptomycin, and 1000 units of Heparin. This stayed at room temperature in the solution until insertion, approximately one hour later. Valves which are not to be used in the experiment on the same day are sterilized with 1 per cent B-propiolactone ${ }^{6)}$ for 2 hours at room temperature, and then are placed in HANK's solution?) and are kept at $4^{\circ} \mathrm{C}$ for periods up to 6 weeks. These preserved valves are removed from HANK's solution just before insertion and are soaked in sterile normal saline at room temperature. Cultures were taken from time to time from the donor valve during the preser-

(Received for Publication, August 18, 1966) 


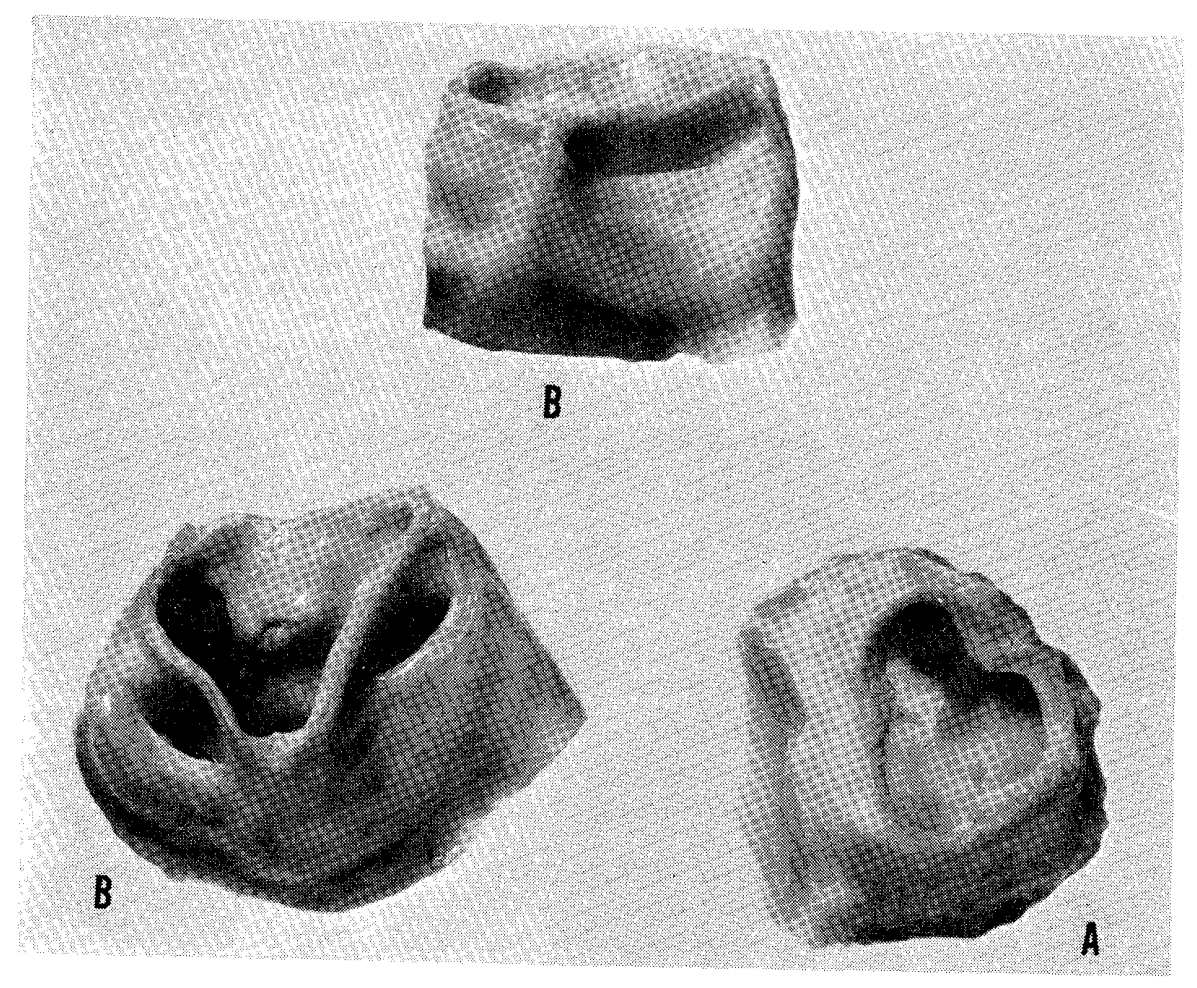

Fig. 1. Donor valve

a) normal aortic valve

b) everted aortic valve

vation period.

Technique of Insertion (Fig. 2)

Healthy, mongrel dogs weighing 15 to $25 \mathrm{~kg}$ are used as recipients. Through a left thoracotomy, the chest is entered through the 5th intercostal space. The cardiopulmonary by-pass is instituted, utilizing a KAY-CROSS oxygenator, and hypothermic cardiac arrest is employed with ice slush. Esophageal temperature is maintained at $28^{\circ} \mathrm{C}$ to $32^{\circ} \mathrm{C}$. The left ventricle is vented from the apex of the heart and connected to low continuous suction. The left atrium is opened and the mitral valve excised leaving a 2 to $3 \mathrm{~mm}$ cuff of valve tissue attached to the circumference of the annulus. The chordae tendineae of the mitral valve are divided close to their insertion on the apices of the papillary muscle.

The donor valve is turned inside-out and placed into the left ventricular cavity. Its original distal border is sutured to the mitral ring with a 5-0 silk continuous suture (1st row of suture). The graft is then turned right side out again and brought back into the left atrial cavity. Then the proximal muscular border of the graft valve is sutured to the left atrial wall with continuous suture (2nd row of suture).

Great care should be taken to obtain equal distribution and proper height of the commissure of the grafted valve. The valve is now in place. The left ventricle is filled with saline solution and the competency of the grafted valve is carefully tested. If the grafted valve fails to be competent, plication of the 2 nd row of sutures at the commissure is of great help.

\section{RESUltS}

Twelve consecutive experiments were completed (Table 1). Only 1 dog died within 24 hours, due to hemothorax. Another dog died of subacute bacterial endocarditis and bacterial thrombi obstructing the grafted valve and pulmonary vein 21 days postoperatively.

One dog was sacrificed for study 2 months postoperatively. The other 9 dogs all survived and appear to be in good health. Currently they are in the $3 \mathrm{rd}$ to 7 th month post-operatively. Two month survival rate is 83 per cent. Among these 9 dogs, 5 dogs have fresh homologous grafts and the other 4 dogs have preserved homologous grafts which were 4 days to 4 weeks in HaNk's solution at $4^{\circ} \mathrm{C}$.

\section{Hemodynamic Studies}

Hemodynamic studies were performed on 3 dogs 2 to 3 months post-operatively. With the chest open, the left atrial and left ventri- 

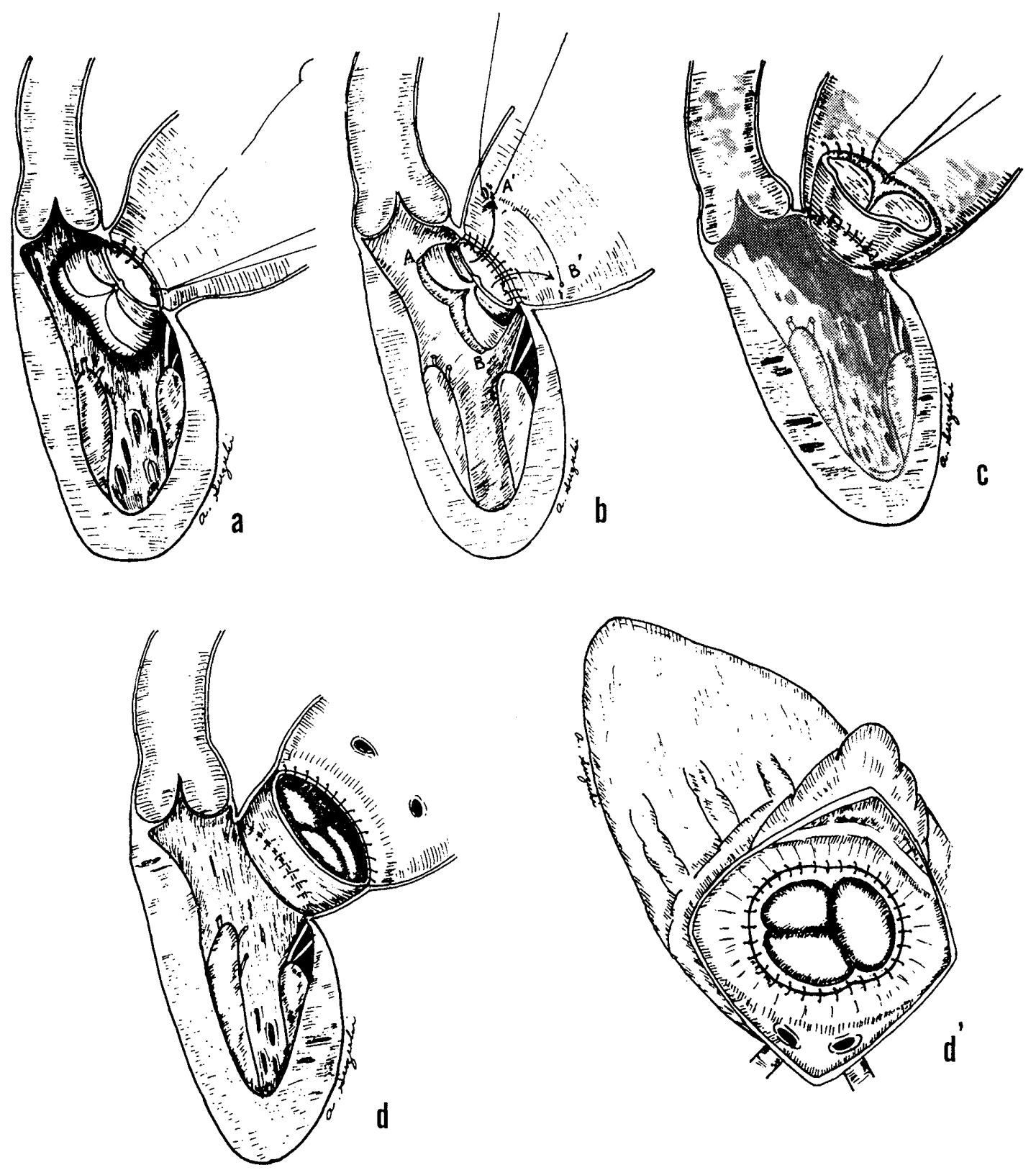

Fig. 2. Technique of insertion of homologous aortic valve to mitral area.

a) Distal end of everted homologous aortic valve is sutured to mitral ring (1st row of suture).

b) The graft is turned right side out and brought back into left atrium.

c) The proximal end of donor valve is sutured to left atrial wall (2nd row of suture).

d) Completion of procedure.

cular pressures were measured simultaneously and compared with their immediate postoperative pressures. A slight increase of pressure gradient across the grafted valve was present (Fig. 3).

Cineangiographic studies were also performed on these 3 dogs at the time of physiological studies. The left atrium was normal in size and dye emptied promptly from the left atrium into the left ventricle. The wide opening of the atrio-ventricular canal indicated no stenosis of the grafted valve.

The left ventriculogram showed competency of the valve and systolic bulging of the aortic semilunar cusps into the atrium without regurgitation of the contrast material (Fig. 4 and 5). 
Table I Results of Mitral Valve Replacement with Homologous Aortic Valve

\begin{tabular}{|c|c|c|c|c|c|c|}
\hline \multicolumn{2}{|c|}{$\begin{array}{c}\text { Experiment } \\
\text { No. }\end{array}$} & \multirow{2}{*}{$\begin{array}{c}\text { Nature of } \\
\text { Grafted } \\
\text { Valve }\end{array}$} & \multirow{2}{*}{$\begin{array}{c}\text { Plication } \\
\text { of Second } \\
\text { Row } \\
\text { No }\end{array}$} & \multirow{2}{*}{$\begin{array}{l}\text { Post-op. } \\
\text { Time } \\
7 \text { Months }\end{array}$} & \multirow{2}{*}{$\begin{array}{c}\text { Follow-UP } \\
\text { Status of } \\
\text { Grafted Valve } \\
\text { Competent }\end{array}$} & \multirow{2}{*}{$\begin{array}{l}\quad \begin{array}{l}\text { Present } \\
\text { Status }\end{array} \\
\text { Alive } \\
\end{array}$} \\
\hline 1) & 234 & & & & & \\
\hline 2) & 255 & Fresh & Yes & 24 Hours & Competent & Dead, Hemothorax \\
\hline 3) & 259 & Fresh & Yes & 5 Months & Competent & Alive \\
\hline 4) & 266 & Fresh & No & 2 Months & Competent & Sacrificed \\
\hline 5) & 267 & Fresh & $Y e s$ & 5 Months & Competent & Alive \\
\hline 6) & 271 & Fresh & Yes & 21 Days & Stenosis Developed & Dead S.B.E. \\
\hline 7$)$ & 272 & Preserved 4 Weeks & Yes & 4 Months & Competent & Alive \\
\hline 8) & 273 & Preserved 4 Weeks & Yes & 4 Months & Competent & Alive \\
\hline 9) & 277 & Fresh & Yes & 4 Months & Competent & Alive \\
\hline 10) & 283 & Preserved 1 Week & Yes & 4 Months & Competent & Alive \\
\hline 11) & 284 & Preserved 4 Days & Yes & 3 Months & Competent & Alive \\
\hline 12) & 287 & Fresh & Yes & 3 Months & Competent & Alive \\
\hline
\end{tabular}

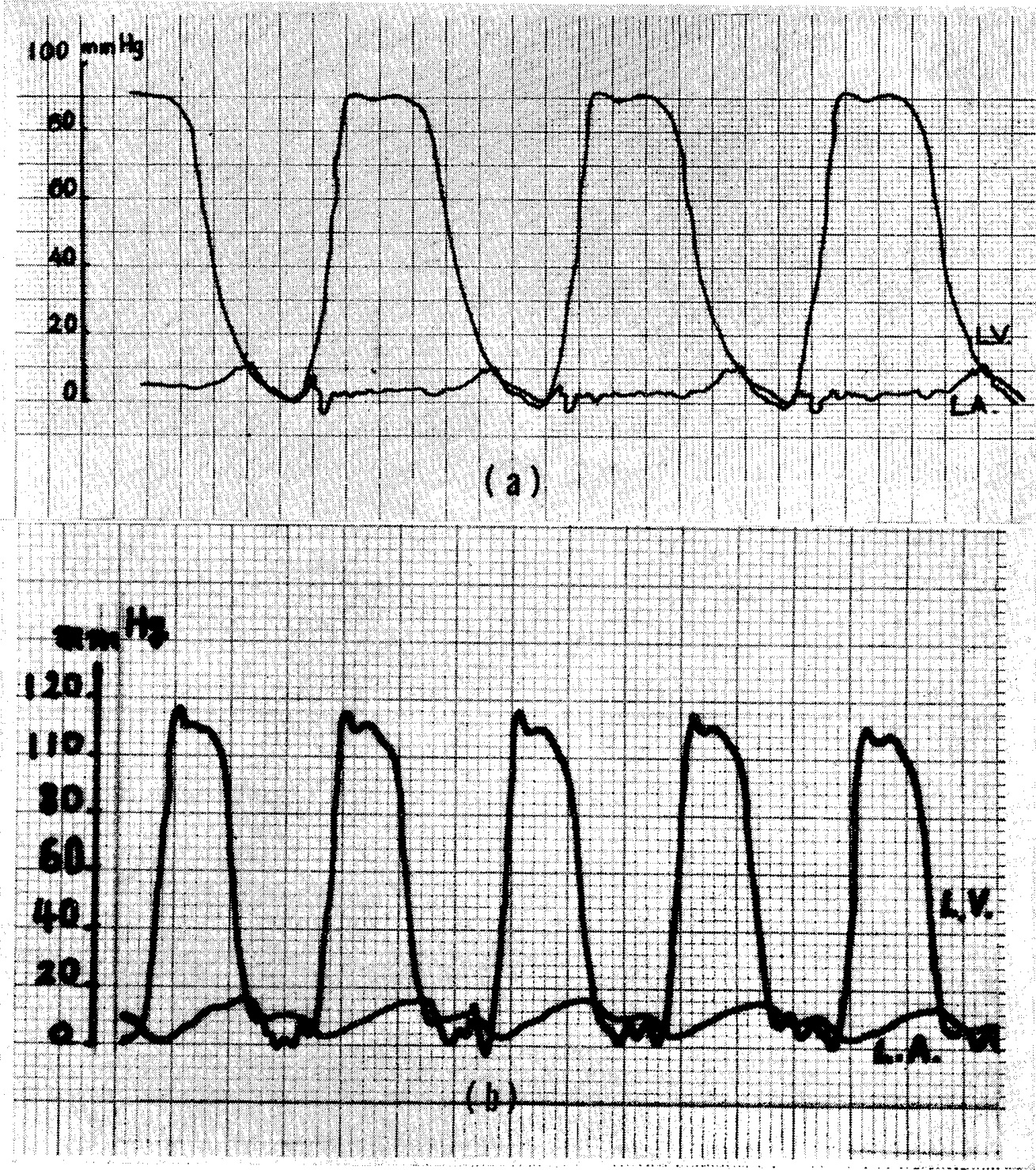

Fig. 3. Simultaneous pressure tracing across the grafted valve.

a) Immediately post-operatively. b) 2 months post-operatively. 
b

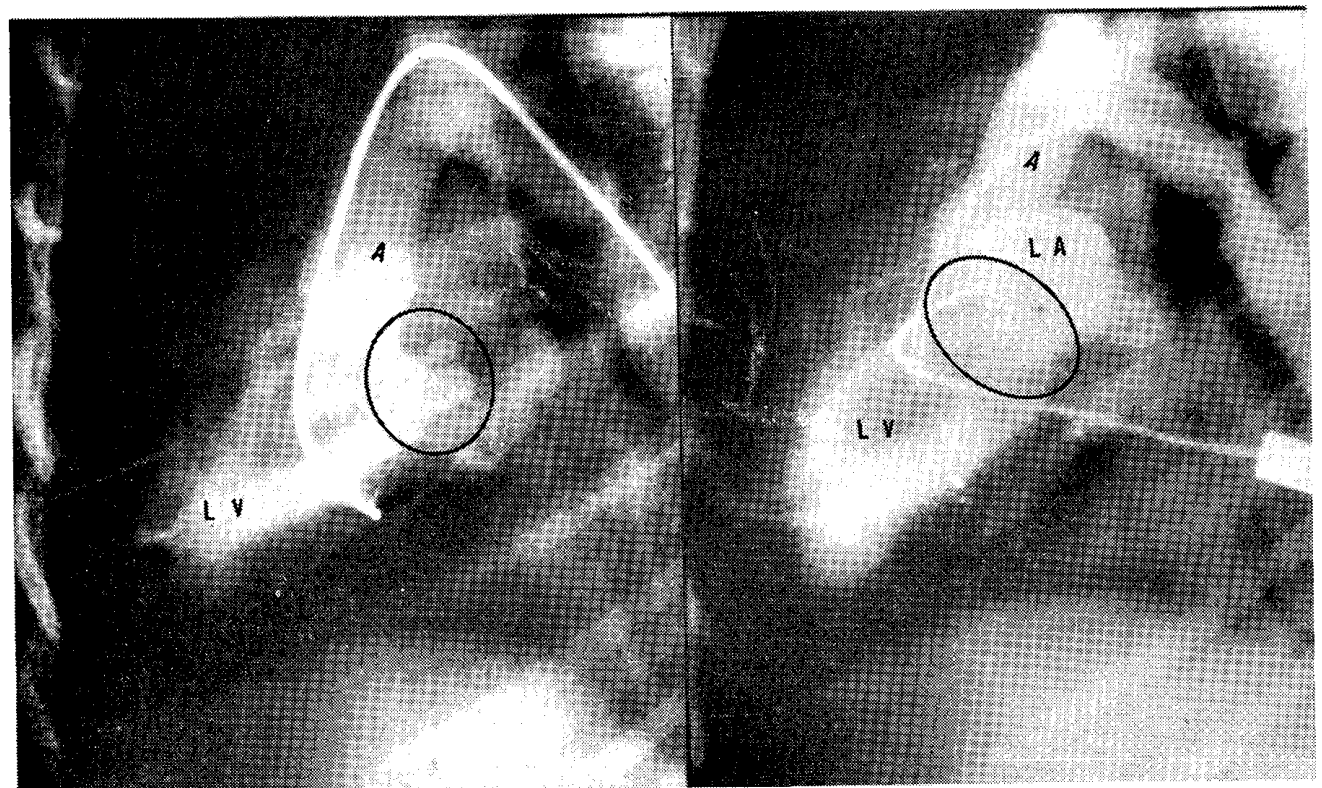

Fig. 4. Angiocardiogram of the post-operative 2 month dog.

a) Left ventriculogram: Note the competency and systolic bulging of semilunar cusps of the grafted valve.

b) Left atrial angiocardiogram: Note normal size of left atrium and wide opening of A-V canal,
L.A. = Left atrium
L.V. = Left ventricle
$\mathrm{A}=$ Aorta

a

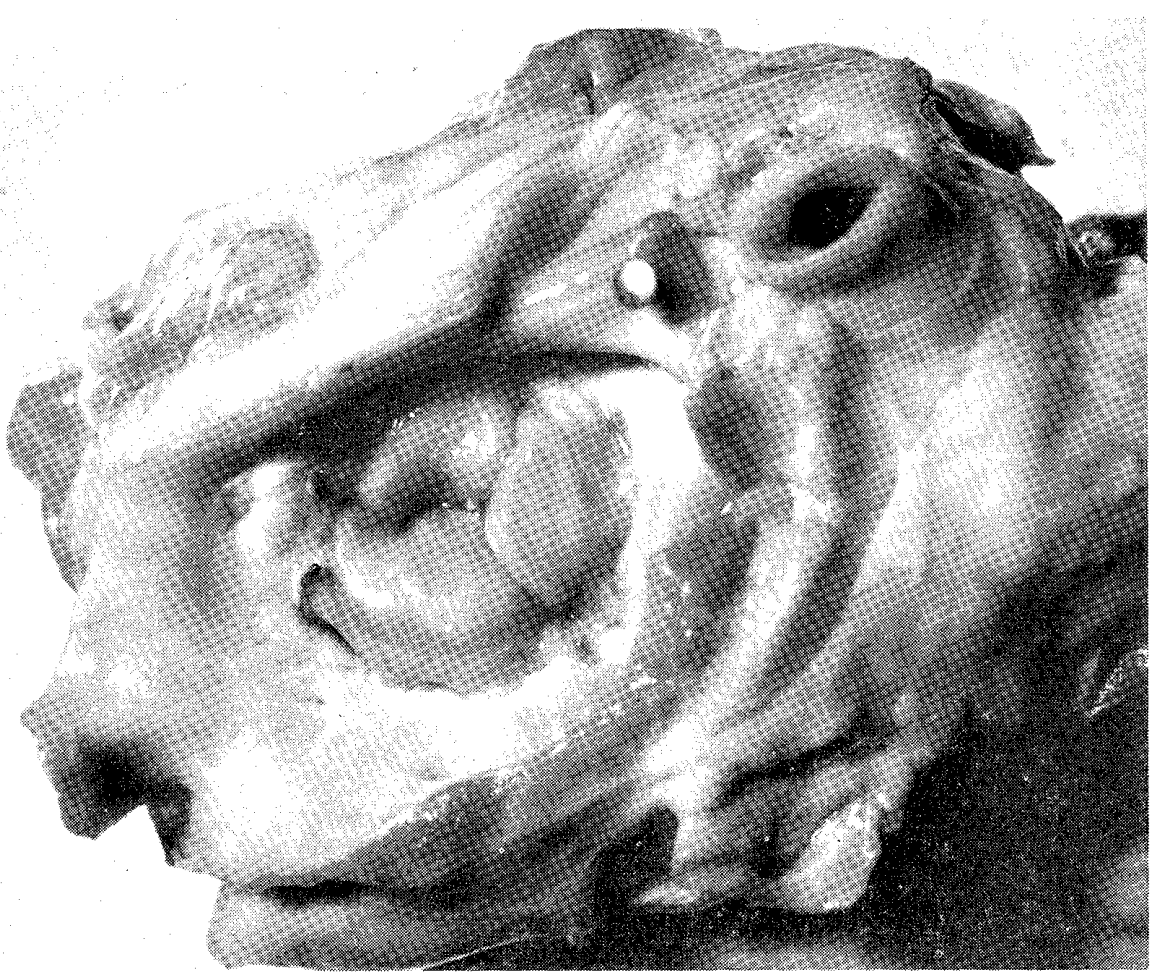

Fig. 5. Specimen from the dog sacrificed 2 months post-operatively.

a) View from left atrium.

Tapanese Circulation Journal Vol. 3o, September 1966 

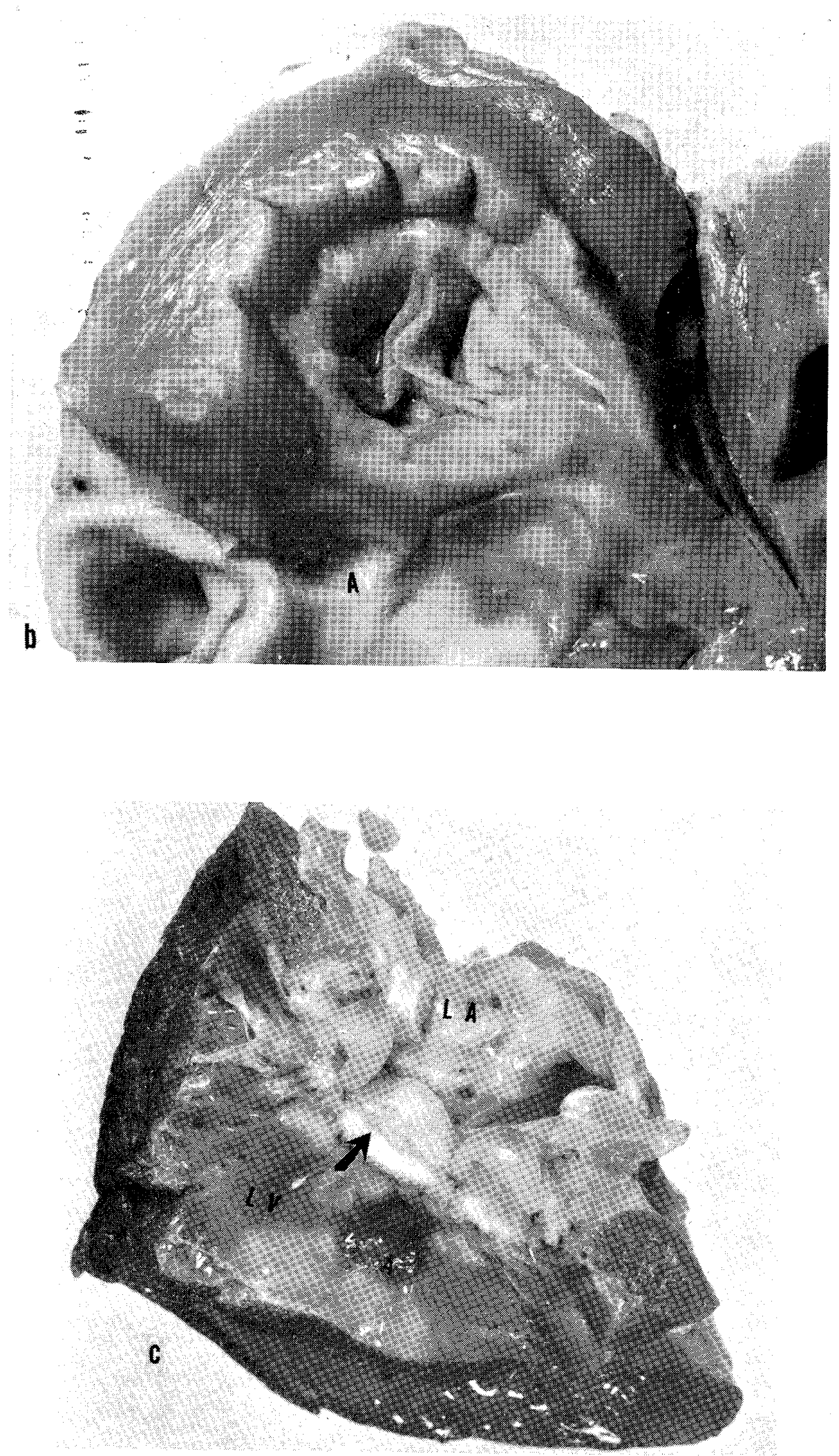

Fig. 5. Specimen from the dog sacrificed 2 months post-operatively.

b) View from left ventricle.

c) Cut through the grafted valve
L.A. = Left atrium
L.V. = Left ventricle
$\mathrm{A}=$ Aorta

Japanese Circulation Journal Vol. 3o, September 1966 


\section{Discussion}

Attempts to replace the mitral valve with autologous or homologous semilunar valves have been performed by many investigators with disappointing results. In 1956, GoRDON MurRay ${ }^{87}$ transplanted homologous aortic valves to the thoracic aorta for the treatment of aortic insufficiency. At the same time, he also suggested the use of homologous aortic valves for mitral insufficiency in such a manner that aortic strips be sutured to the left ventricular wall as chordae tendineae, and that the annulus fibrosis of the grafted valve be sutured to the mitral ring. Later, WILLMAN and his associates ${ }^{9)}$ replaced the canine mitral valve under direct vision, in the manner suggested by MurRaY with the homologous aortic valve. They used 2 extensions of the aortic wall of grafted valve as chordae tendineae, and anchored them to the left ventricular wall. The aortic ring of the grafted valve was sutured to the recipient's mitral ring. In their 23 experiments, 16 animals died within 2 weeks due to technical misadventure, and 4 animals died within one month because of development of mitral regurgitation due to separation of the suture line at the mitral annulus. Dogs which survived 1,2 , and 5 months all died due to mitral regurgitation. At autopsy, homograft aortic valves were found to be grossly distorted, contracted, and covered with bacterial vegetations.

Recently, McKenzie and his associates ${ }^{10)}$ from the Mayo Clinic, employed a similar technique using 3 aortic strips instead of 2 . The entire aortic wall of the grafted valve was reinforced with 3 pieces of Teflon felt to secure the fixation. It was hoped that the Teflon felt would allow fibrous tissue to grow with good healing between the aortic strips and the ventricular myocardium. Their experimental results are far superior to Willman's. They obtained 4 long-term survivals, ranging from 13 months to 17 months. Although they did not produce any mitral regurgitation through the homografted valves in their experiments, their hemodynamic and cineangiographic studies showed increasing evidence of mitral stenosis due to contraction of the aortic cuff of the grafted valve. The cusps of the grafted valve remained pliable, mobile, and only slightly thickened up to 12 months after insertion.

From our clinical and experimental experience the use of chordae tendineae for mitral valve replacement is not advisable because of the difficulty of fixation and adjustment of length. These factors led us to develop a unique technique which eliminates the use of chordae tendineae. Lower and associates ${ }^{11)}$ described the technique of inserting autologous pulmonic valves into the mitral valve area in such a fasion that the valve ring itself was anchored to the left atrial wall, and the distal border of the grafted valve was sutured to the mitral annulus. They demonstrated that 12 out of 22 dogs (55 per cent) showed insufficiency of the grafted valve, due to either disruption of the suture line or inadequate coaptation of the cusps.

We feel that the homologous aortic valve is far superior for mitral replacement to the autologous pulmonic valve, because of the deep contour of the aortic sinus of Valsalva, the high pressure tolerance of the aortic valve, and a large selection of homologous valve sizes, instead of one in the case of the autologous pulmonic valve, and that their creation of pulmonic insufficiency also is questionable.

It is generally agreed that a homologous graft has high susceptibility to infection (WILLman, McKenzie, Berghuis) ${ }^{12}$. We believe that the disappointing results of homologous valve transplantation by some investigators were largely due to infection. The careful handling of the graft and proper post-operative care minimize the incidence of infection. Only one dog died of septicemia in our experiments up to date, and the animals sacrificed for study showed no evidence of infection.

The long term fate of the homologous cardiac valve has been a matter of great controversy. LAM $^{13)}$ in 1952 has suggested that the aortic valve homograft does not continue to function when placed in the thoracic aorta of the dog. However, he also suggested that destruction of the recipient animal's aortic valve, by increasing the functional stimulus, would promote the survival of the homograft 
valve in the thoracic aorta. BREWIN ${ }^{14)}$ in 1956 , repeated similar experiments with disappointing results and questioned the validity of LAM's concept. Also, similar experiments were reported by Beall, Morris, Cooley and De $\mathrm{BAKEY}^{16)}$ in 1961. In contrast to these unsatisfactory results, clinical experience from Toronto (Murray, 1956, Kerwin, Lenski and $\left.\mathrm{WILSON}^{16)}, 1962\right)$, where homografted aortic valves have been inserted in the descending thoracic aorta in a patient with severe aortic imcompetence, showed that these valves will function normally up to $61 / 2$ years.

Since 1962, a large number of homografted aortic valve replacements into the subcoronary area have been reported by Ross and BARRATTBOYES $^{(2) 3) 4)}$. They showed that the homografted aortic valve is a very satisfactory type of replacement, and that homografted valve leaflets have shown no microscopic change in structure up to 3 years after insertion. They continue to function satisfactorily clinically, without evidence of any progressive change. However, approximately 50 per cent of cases had a diastolic murmur, in spite of clinical improvement.

We feel the homologous aortic valve is excellent material with which to replace the human mitral valve in selected cases, when proper technique affords complete competency.

\section{Case Report}

A 47 year old white female with the chief complaint of shortness of breath was admitted for elective open heart surgery. A few years ago, the patient started to develop exertional dyspnea, orthopnea, and occasional chest pain. She developed congestive heart failure and was placed on digitalis and diuretics.

Cardiac catheterization, performed at St. Vincent Charity Hospital in May, 1965, disclosed disease of the aortic, mitral, and tricuspid valves. Surgery was advised at that time, but the patient refused. Her general condition continued to deteriorate, so she subsequently agreed to surgery. On examination, she was found to be small and thin. Pulse was irregular, and rate was $96 / \mathrm{min}$. Blood pressure was $140 / 80 \mathrm{~mm} \mathrm{Hg}$; respiration, 22/minute. Venous pressure was 18 $\mathrm{cm} \mathrm{H}_{2} \mathrm{O}$ at the antecubital vein. It increased $2 \mathrm{~cm}$. upon pressure on the liver region. P.M.I. was in the left, 5th intercostal space, iust outside of the mid-clavicular line. Grade 2-6 presystolic rumble and grade 3-6 highpitched pansystolic murmur was best noted at the apex. $M_{1}$ was slightly accentuated, and $\mathrm{P}_{2}$ was greater than $\mathrm{A}_{2}$. There was a faint diastolic murmur at the left 4 th intercostal space.

The cardiac catheterization done in 1965 showed that the pressures were markedly elevated in the right ventricle $\left(88 / 1 \mathrm{D}_{2} 7\right)$ and pulmonary circuit.

There was no systolic gradient across the aortic valve. The left ventricular end-diastolic pressure was normal but the end-diastolic pressure in the right atrium $(7 \mathrm{~mm} \mathrm{Hg})$ and ventricle $(7 \mathrm{~mm} \mathrm{Hg})$ were slightly elevated. There was no diastolic gradient across the tricuspid valve.

The E.C.G. showed right axis deviation, $1^{\circ}$ A-V block, right ventricular hypertrophy, and left atrial enlargement. The vectorcardiogram showed right bundle branch block and left atrial enlargement. Fluoroscopy and chest $\mathrm{X}$-ray showed a prominent left atrium and pulmonary artery contour in the P-A projection. A double atrial shadow was also seen. Cineangiocardiogram revealed marked trabeculation of the right ventricular wall. There was minimal regurgitation across the tricuspid valve. The L.A. and its appendage were markedly dilated. A gradient in the dye concentration across the mitral valve persisted during several cardiac cycles, in diastole as well as in systole. On the left ventriculogram there was noted a small left ventricular cavity and moderate mitral regurgitation. The aortogram showed a minimal degree of aortic regurgitation. The coronary arteriogram was essentially normal. From above, the diagnosis of a severe degree of mitral stenosis, a moderate degree of mitral regurgitation, and minimal tricuspid and aortic regurgitation were confirmed.

On March 21, 1966, the operation was carried out. The patient was placed in a right semi-thoracotomy position. Through an anterio-lateral thoracotomy, the chest was entered 


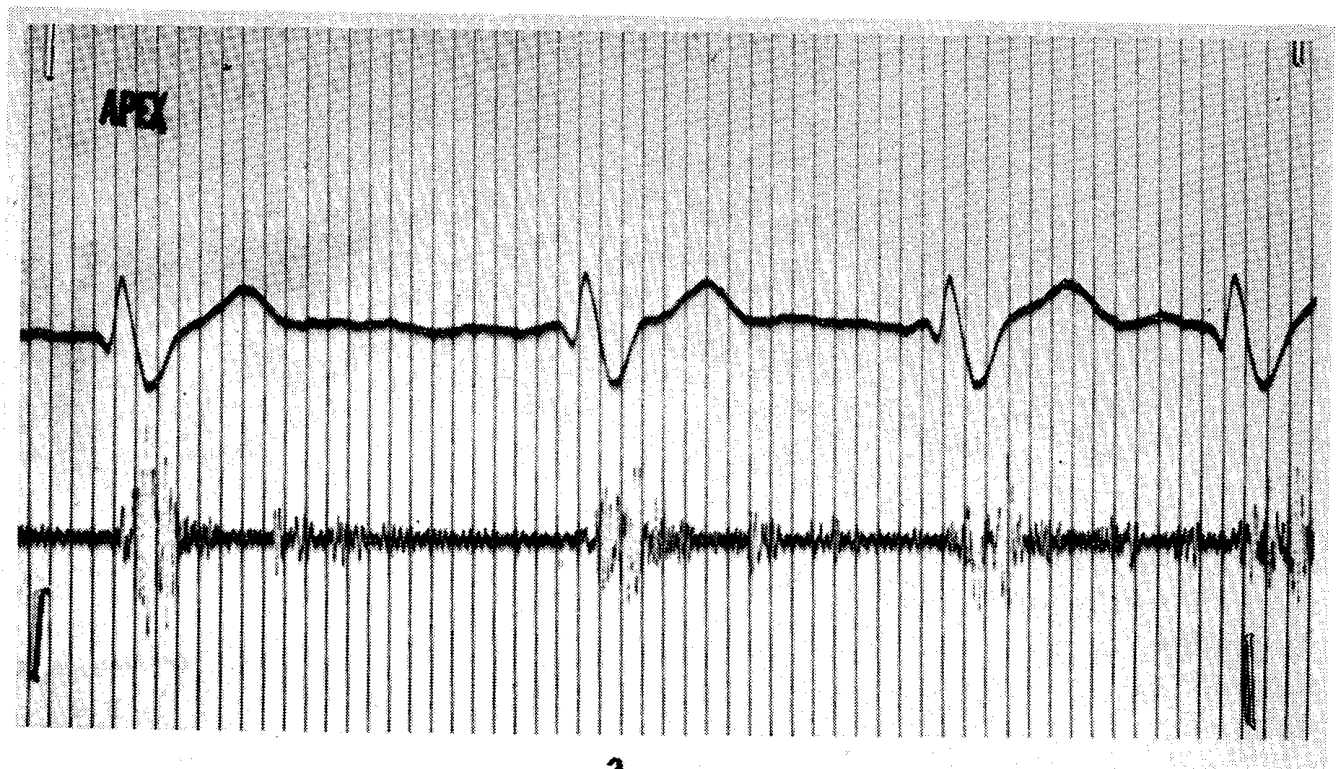

a

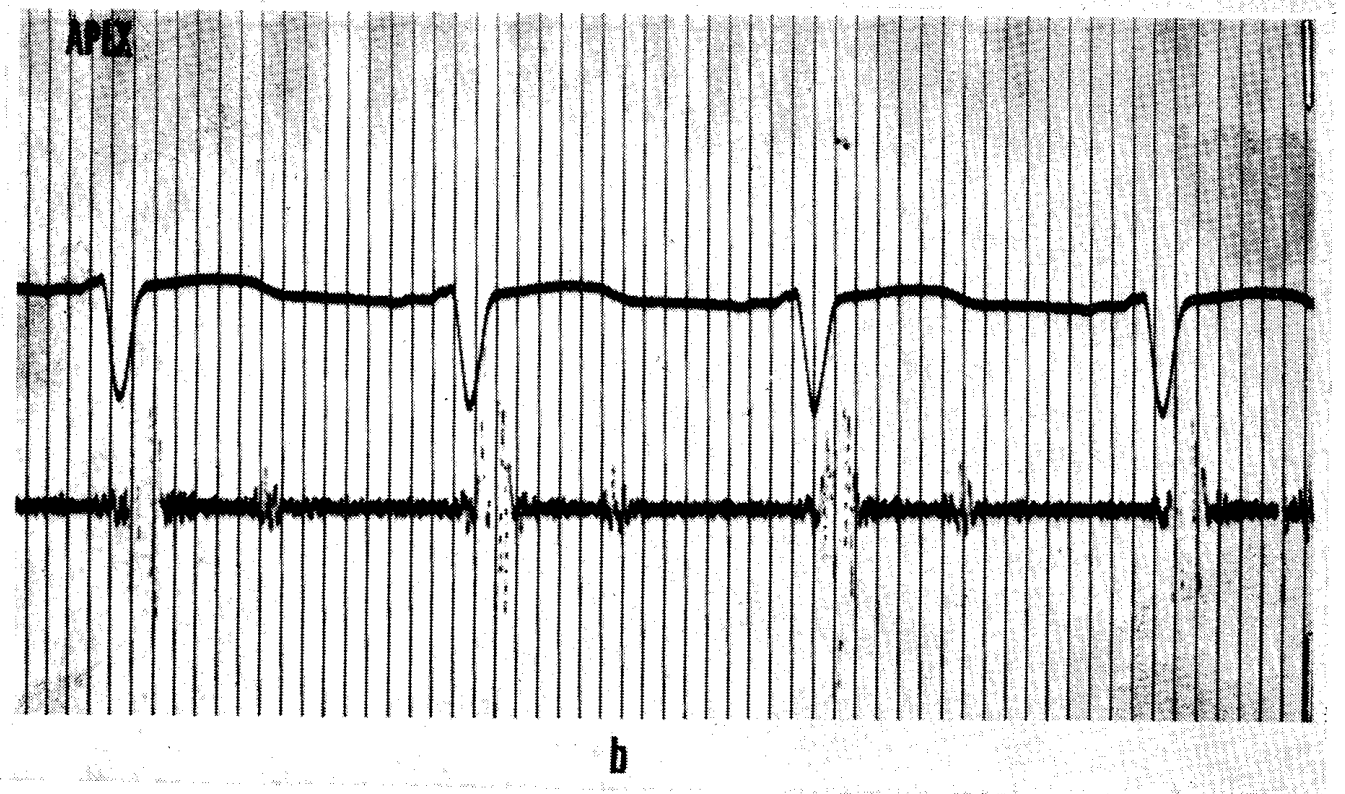

Fig. 6. Phonocardiogram at apex.

a) Pre-operatively: Systolic murmur and presystolic murmur, opening snap 0.06 seconds after $\mathrm{S}_{2}$.

b) Post-operatively: No significant murmur.

at the right, 4th intercostal space, the pericardium was opened, and the heart was exposed. The right atrium was enlarged, with a fairly high pressure. Finger examination revealed a minimal degree of tricuspid regurgitation which did not require any surgical correction. The pulmonary artery was tense and enlarged. The left atrium was markedly enlarged, with severely elevated pressure.

The cardiopulmonary by-pass was instituted, utilizing a KAY-CROSS oxygenator, with a flow rate of $40-45 \mathrm{cc} / \mathrm{kg} / \mathrm{min}$. and esophageal temperature of $28-30^{\circ} \mathrm{C}$. The left atrium was then opened and the mitral valve was exposed. A severely deformed, stenosed, calcified mitral valve was found. Fortunately, the mitral annulus was free of calcification.

The mitral valve was completely removed from the mitral annulus, leaving a cuff of approximately $5 \mathrm{~mm}$ in length. A few chordae tendineae were preserved on the posterior leaflet. A mitral prosthesis, the KAY-SuzUKI 
discoid valve, was considered. However, the left ventricular cavity was extremely small and the ventricular septum was bulging into the left ventricular cavity. This would definitely interfere with the disc action of the valve. Therefore, this appeared to be the perfect indication for an inverted homologous aortic valve implant in the mitral area. With the upside-down homologous aortic valve completely located in the left atrium, there would be nothing to interfere with ventricular action.

The mitral orifice was measured and the homologous aortic valve which was closest in size was chosen. This valve was 3 weeks old and had been preserved in Hank's solution at $4^{\circ} \mathrm{C}$. The homologous aortic valve was then sutured in the manner described in the previous chapter.

The grafted valve was tested with saline and found to have no regurgitation. After evacuation of air from the left side of the heart, the left atriotomy was closed with a continuous suture. By-pass was then gradually discontinued and the heart took over very nicely. The left atrium was soft and no systolic thrill was palpable.

The post-operative course was completely uneventful, except for a few episodes of atrial arrythmia and atrial flutter, with 2-1 block. The patient was placed on digitalis and penicillin, 10 million units per 24 hours, and streptomycin 0.5 gm every 12 hours for 7 days. She was then changed to maintenance dose of oral penicillin. Three weeks post-operatively the patient was discharged in excellent condition. At the present time, the patient is in her 4th post-operative month; she is able to do all her house work and is free from all symptoms of mitral disease. (Fig. 6).

\section{Summary}

A new technique of mitral valve replacement with a homologous aortic valve has been described. The operation can be carried out with very low mortality and gives excellent hemodynamic results. No thromboembolic complications have been observed.

One successful human mitral replacement with upside-down homologous aortic valve in left atrium was reported. We believe that the technique described in this paper is quite unique and gives excellent results for human mitral valve replacement in selected cases.

\section{REFERENCES}

1) Kay, E.B., Suzuki, A., Demaney, M. and Zimmerman, H.A., Comparison of ball and disc valves for mitral valve replacement. J. Am. College of Cardiology In Press.

2) Ross, D.N., Homotransplantation of the aortic valve in the subcoronary position. J. Thoracic $\mathcal{E}$ Cardiovas. Surg. 49: 713, 1964.

3) Ross, D.N., Personal communication at the Cleveland Cilnic, May, 1966.

4) Barrattr Boyes, B.G., Homograft aortic valve replacement in aortic incompetence and stenosis. Thorax 19 : 131, 1964.

5) Heimbecker, R.O., Baird, R.J., Lagos, T.Z., Vargo, A.T. and Greenwood, W.F., Homograft replacement of the human mitral valve. Canad. M.A.J. 86:805 1962.

6) Rains, A.J., Crawford, N., Sharpe, S.H., Shrewsbury, J.F.D. and Barson, G.J., Management of an artery-graft bank with special reference to sterilization by B-propiolactone.

7) Gross, R.E., Bill, A.H. and Peirce, E.C., Methods for preservation and transplantation of arterial graft. Surg. Gynec. \& Obst. Vol. 88. June, 1949.

8) Murray, G., Homologous aortic-valve-segment transplants as surgical treatment for aortic valve and mitral insufficiency. Angiology $7:$ 466, 1956.

9) Willman, V.L., Zafircopoulos, P. and Hanlon, C.R., Replacement of the mitral valve with homograft aortic valve. In Merendino, K.A., Prosthetic valve for cardiac surgery, Springfield, Ill., 1961. Charles C. Thomas, Publisher, pp. 142-148.

10) McKenzie, M.B., Titus, J.L., Rastelli, G.C., Pappas, G. and Ellis, H.F., Replacement of the canine mitral valve with semilunar valves. J. Thoracic and Cardiovas. Surg. 51 : 2-168, 1966.

11) Lower, R.R., Stofer, R.C. and Shumway, N.E., Total excision of the mitral valve and replacement with the autologous pulmonic valve. J. Thoracic $\&$ Cardiovas. Surg. 42 : 696, 1961.

12) Berghuis, J., Rastelli, G.C., Van Vliet, P.D., Titus, J.L., Swan, H.J.C. and Ellis, F.H., Jr., Homotransplatation of the canine mitral valve. Circulation 29: 49, 1964.

13) Lam, C.R., Aram, H.H. and Munnell, E.R., An experimental study of aortic valve homograft. Surg., Gynec. \& Obst. $94: 129,1952$.

14) Brewin, E.G., The use of tissue transplants in the surgery of cardiac valvular disease, An experimental study, Guy's Hosp, Rep. 105 : 329, 1956.

15( Beall, A.C., Morris, G.C., Jr., Cooley, D.A. and De Bakey, M.E., Homotransplantation of the aortic valve. J. Thoracic Surg. 42: 497, 1961.

16) Kerwin, A. J., Lenkei, S.C. and Wilson, D.R., Aortic-valve homograft in the treatment of aortic insufficiency: Report of nine cases with one followed for 6 years. New England J. Med. 266: $852,1962$. 